Asian Journal of Managerial Science

ISSN: 2249-6300 Vol.8 No.1, 2019, pp. 1-5

(C)The Research Publication, www.trp.org.in

\title{
Performance Analysis of the Index Mutual Fund
}

\author{
Yasmeen Bano ${ }^{1}$ and S. Vasantha ${ }^{2}$ \\ ${ }^{1}$ Research Scholar, ${ }^{2}$ Professor \& Research Supervisor (Corresponding Author), \\ ${ }^{1 \& 2}$ School of Management Studies, \\ Vels Institute of Science, Technology \& Advanced Studies (VISTAS), Chennai, Tamil Nadu, India \\ E-Mail: yasmeen11bano@gmail.com, vasantha.sms@velsuniv.ac.in
}

\begin{abstract}
A mutual fund is a professionally managed investment fund that pools together the savings of a number of investors who shares the common financial goals. These investors may be retail or institutional in nature. It offers small or individual investors access to professionally managed portfolios of equities, bonds and other securities. The paper is the study of the performance of Index fund. This is analyzed empirically since the period of $2012-2017$. The main objective of this research is to evaluate the performance of Index funds. The study examined three parameters such as active returns, tracking error and Jensen's alpha. In this paper the data has been collected from the secondary sources.

Keywords: Financial Performance, Index Fund, Risk Adjusted Return, Tracking Error
\end{abstract}

\section{INTRODUCTION}

An Index Fund is a form of mutual fund that invests in a specific set of stocks of an index like BSE Sensex or NSE NIFTY. A portfolio of an index fund built to inform or track the additives of a market index and it offers massive marketplace exposure low portfolio turnover and low operating expenses These finances observe the unique standards or regulations such as Efficient tax management or reducing tracking error that stay in location, there may be no matter the country of the markets. The main advantage of index funds for investors lies in its cost. Since the mutual fund require only passive fund management, they are much cheaper than more actively managed fund in which portfolio managers make an effort to choose the right stocks.

\section{A. Key Features of an Index Fund}

1. An Index Fund objective to supply returns which can be similar to the whole returns of common stocks as represented by means of the index tracked - BSE Sensex or NSE NIFTY.

2. It is suitable for new investors or those who want an exposure to equity as an asset class without the complexities of choosing specific stocks or high performing mutual funds. When one has a medium to long time invest horizon, an index fund systematic investment plan is a better funding alternative due to higher potential for capital appreciation and building wealth.

\section{LITERATURE REVIEW}

Smita Shukla, Rakesh Malusare (2016), studies different types of mutual fund schemes making investment in Overseas Securities and categorizes those schemes on the basis of their investment portfolio. The Paper compares the returns on Overseas Mutual Fund Schemes in comparison to similar portfolio schemes and return on them generated in US and China and also compares the returns of Mutual Fund Schemes investing abroad with average returns generated in similar broad portfolio schemes in India.

Muralidhar Prasad Ayaluru (2016) evaluates the performance of mutual fund schemes. The study selected 10 open ended Equity mutual fund schemes which were offered by the Reliance Mutual Fund.

P. Krishna Prasanna (2012) studies the characteristics and growth pattern of all the 82 Exchange Traded schemes. The schemes are floated and traded on Indian Stock markets. The study measures the performance using DEA (Data Envelopment Analysis) method. The analysis reveals that the overseas fund of funds as well as the Gold funds were able to mobilize greater resources and were able to impress the investors.

S. Narend (2014) presents a comparative study of the performance of ETFs and index funds. The study has done empirically since the period of their respective initiation till July 2013. The study used three parameters for the analysis of the performance such as active returns, tracking error and Jensen's alpha. The analysis shows that ETFs are performing good compare to the index mutual funds.

Cheng-Ru Wu (2008) presents a framework of assessable mutual fund performance The study tries to find how investors assess mutual fund performance which is not only based on quantitative but also qualitative criteria. The study used the modified Delphi method and the analytical hierarchy process (AHP) to design an assessment method for evaluating mutual fund performance.

Vikas Choudhary, and Preeti Sehgal Chawla (2014), represents that majority of funds selected for study have outperformed. The study analyzed the data using Sharpe Ratio as well as Treynor Ratio. The analysis was 
accomplished by assessing various financial tests like Average Return, Sharpe Ratio, Treynor Ratio, Standard Deviation, Beta and Coefficient of Determination.

M. Jayanthi, S. Malathy, T. Radhulya (2013), analyse the gold ETFs and compare the historical data of various gold ETFs in India .The study tracks the performance on daily, weekly, monthly, quarterly and yearly basis. The study showed that many of the gold ETFs currently available in the Indian market exhibit a large deviation from actual gold returns. This problem is more prominent in India than in developed markets.

Shivangi Agarwal, Nawazish Mirza (2017), analyzes the performance of selected mutual fund schemes on the basis of risk and return. The study also compares the performance of the selected mutual fund schemes with their benchmark index. The study also addresses multiple research issues. The study also rank funds on the basis of performance and suggest strategies to invest in a mutual fund.

Inderjit Kaur and K.P. Kaushik (2015), present the study based on the theory of planned behavior, the study observed the, attitude (perception for outcome), effect of awareness and socioeconomic conditions of an investor on his investment behavior towards mutual funds.

The research said that investment behaviour could be explained with awareness, perception and socioeconomic characteristics of individual investors. Better awareness related to various aspects

\section{OBJECTIVES OF THE RESEARCH}

1. To study about the performance of Nifty INDEX funds

2. To evaluate the risk adjusted return of Nifty INDEX funds.

3. To examine the tracking error and information ratio.

\section{RESEARCH METHODOLOGY}

This analysis is based on the performance of Nifty INDEX funds. The study selected five INDEX funds for the analysis of data such as IDBI Nifty Index Fund, UTI Nifty Index Fund, HDFC Index Fund - Nifty Plan, SBI Nifty Index Fund, Tata Index Fund-Nifty Plan (G). The research problem is solved by analyzing the data in a systematic way. The main source of the information is secondary data which is suitable for the purpose of the study. The secondary data were collected from the financial report of funds. The study examines the excess return, active return, risk adjusted returns, Sharpe ratio and Treynor ratio. The period of the study were considered from 2012 to 2017.

TABLE I NIFTY INDEX FUNDS

\begin{tabular}{|l|l|}
\hline \multicolumn{1}{|c|}{ Index fund } & Benchmark \\
\hline IDBI Nifty Index Fund & Nifty Sensex \\
\hline UTI Nifty Index Fund & Nifty Sensex \\
\hline HDFC Index Fund - Nifty Plan & Nifty Sensex \\
\hline SBI Nifty Index Fund & Nifty Sensex \\
\hline Tata Index Fund-Nifty Plan(G) & Nifty Sensex \\
\hline
\end{tabular}

\section{RESULTS AND DISCUSSION}

The study has taken five open-ended Index fund to analyze the performance which were launched during the period of 2000-2010.The investment objective of the schemes is to provide returns before expenses that closely correspond to the total returns of the S\&P CNX Nifty subject, to tracking errors. The performance of Index funds was measured by analyzing their active returns and excess returns. The analysis showed that the Index fund considered in this study the better performance. Here (in table II) shows the characteristics of five Index funds given below.

TABLE II CHARACTERISTICS OF INDEX FUNDS

\begin{tabular}{|c|l|c|c|c|c|c|}
\hline S. No. & \multicolumn{1}{|c|}{ Index Funds } & $\begin{array}{c}\text { Underlying } \\
\text { Index }\end{array}$ & Launch date & Fund Type & $\begin{array}{c}\text { AUM AS ON dec, } \\
\mathbf{2 0 1 7} \text { (In crores) }\end{array}$ & $\begin{array}{c}\text { Minimum Investment } \\
\text { (In INR) }\end{array}$ \\
\hline 1 & IDBI Nifty Index Fund & NIFTY & 25-Jun-10 & Open-ended & 218 & 5,000 \\
\hline 2 & UTI Nifty Index Fund & NIFTY & 6-Mar-00 & Open-ended & 716 & 5,000 \\
\hline 3 & $\begin{array}{l}\text { HDFC Index Fund - } \\
\text { Nifty Plan }\end{array}$ & NIFTY & 17-Jul-02 & Open-ended & 312 & 5,000 \\
\hline 4 & SBI Nifty Index Fund & NIFTY & 4-Feb-02 & Open-ended & 239 & 5,000 \\
\hline 5 & $\begin{array}{l}\text { Tata Index Fund-Nifty } \\
\text { Plan(G) }\end{array}$ & NIFTY & 25-Feb-03 & Open-ended & 6.58 & 5,000 \\
\hline
\end{tabular}

\section{A. Active Returns and Excess Returns of Index Funds}

Excess returns are investment returns from a security or portfolio that exceeds the riskless rate on a security generally perceived to be risk free and Active return is the percentage gain or loss of an investment relative to the investment's benchmark. 
TABLE III IDBI NifTy INDEX Fund- ANNUALIZEd RETURNS (2012 - 2017)

\begin{tabular}{|c|c|c|c|c|c|c|c|}
\hline Year & Nifty sensex & Rm in \% & NAV & Rp in \% & Rf & Excess return(Rp-Rf) & Active return (Rp-Rm) \\
\hline 2012 & 5410.56 & 1.70 & 10.10 & 0.14 & 8.03 & -7.89 & -1.56 \\
\hline 2013 & 5908.09 & 9.20 & 11.17 & 10.65 & 8.85 & 1.80 & 1.46 \\
\hline 2014 & 7453.50 & 26.16 & 13.93 & 24.65 & 8.22 & 16.43 & -1.51 \\
\hline 2015 & 8298.82 & 11.34 & 15.61 & 12.06 & 7.25 & 4.81 & 0.72 \\
\hline 2016 & 8138.21 & -1.94 & 15.14 & -2.98 & 6.34 & -9.32 & -1.04 \\
\hline 2017 & $9,661.42$ & 18.72 & 17.80 & 17.54 & 6.42 & 11.12 & -1.18 \\
\hline
\end{tabular}

Table III shows the excess returns and active returns of IDBI Nifty index fund during the period of 2012-2017.The scheme got highest excess return $16.43 \%$ in the period of
2014 and highest active return 0.72 in the period of 2015 . And the lowest excess return is -9.32 in the period of 2016 , the lowest active return is -1.56 in the period of 2012 .

TABLE IV UTI NIFTY INDEX FUND- ANNUALIZED RETURNS (2012 - 2017)

\begin{tabular}{|c|c|c|c|c|c|c|c|}
\hline Year & Nifty sensex & Rm in \% & NAV & Rp in \% & Rf & Excess return(Rp-Rf) & Active return (Rp-Rm) \\
\hline 2012 & 5410.56 & 1.70 & 33.31 & 0.31 & 8.03 & -7.72 & -1.40 \\
\hline 2013 & 5908.09 & 9.20 & 36.85 & 10.64 & 8.85 & 1.79 & 1.45 \\
\hline 2014 & 7453.50 & 26.16 & 46.06 & 24.99 & 8.22 & 16.77 & -1.17 \\
\hline 2015 & 8298.82 & 11.34 & 52.09 & 13.09 & 7.25 & 5.84 & 1.75 \\
\hline 2016 & 8138.21 & -1.94 & 51.36 & -1.39 & 6.34 & -7.73 & 0.55 \\
\hline 2017 & $9,661.42$ & 18.72 & 61.33 & 19.40 & 6.42 & 12.98 & 0.68 \\
\hline
\end{tabular}

The table IV examined the excess returns and active returns for the UTI Nifty index fund during the period of 20122017. The highest excess return is 16.77 in the period of
2014 and lowest excess return is -7.73 in the period of 2016, the highest active return is 1.75 in the period of 2015 and the lowest active return is -1.40 in the period of 2012 .

TABLE V HDFC INDEX FUND NIFTy PLAN- ANNUALIZED RETURNS (2012 - 2017)

\begin{tabular}{|c|c|c|c|c|c|c|c|}
\hline Year & Nifty sensex & Rm in \% & NAV & Rp in \% & Rf & Excess return(Rp-Rf) & Active return (Rp-Rm) \\
\hline 2012 & 5410.56 & 1.70 & 46.17 & -0.16 & 8.03 & -8.19 & -1.86 \\
\hline 2013 & 5908.09 & 9.20 & 51.16 & 10.80 & 8.85 & 1.95 & 1.60 \\
\hline 2014 & 7453.50 & 26.16 & 64.26 & 25.61 & 8.22 & 17.39 & -0.55 \\
\hline 2015 & 8298.82 & 11.34 & 72.83 & 13.33 & 7.25 & 6.08 & 1.99 \\
\hline 2016 & 8138.21 & -1.94 & 71.78 & -1.44 & 6.34 & -7.78 & 0.49 \\
\hline 2017 & $9,661.42$ & 18.72 & 85.58 & 19.23 & 6.42 & 12.81 & 0.52 \\
\hline
\end{tabular}

The table $\mathrm{V}$ analyzed the excess returns and active returns of HDFC index fund nifty plan during the period of 20122017. Here the table shows highest excess return in the period of 2014 which is 17.39 and the lowest excess return in the period of 2012 which is -8.19 , the highest active return in the period of 2015 which is 1.99 and lowest active return in the period of 2012 which is -1.86 .

TABLE Vi SBi NifTy INDEX FUnD- ANNUALIZEd RETURNS (2012 - 2017)

\begin{tabular}{|c|c|c|c|c|c|c|c|}
\hline Year & Nifty sensex & Rm in \% & NAV & Rp in \% & Rf & Excess return(Rp-Rf) & Active return (Rp-Rm) \\
\hline 2012 & 5410.56 & 1.70 & 45.72 & 0.54 & 8.03 & -7.49 & -1.17 \\
\hline 2013 & 5908.09 & 9.20 & 50.46 & 10.37 & 8.85 & 1.52 & 1.18 \\
\hline 2014 & 7453.50 & 26.16 & 62.55 & 23.95 & 8.22 & 15.73 & -2.20 \\
\hline 2015 & 8298.82 & 11.34 & 69.98 & 11.88 & 7.25 & 4.63 & 0.54 \\
\hline 2016 & 8138.21 & -1.94 & 68.51 & -2.10 & 6.34 & -8.44 & -0.16 \\
\hline 2017 & $9,661.42$ & 18.72 & 81.44 & 18.87 & 6.42 & 12.45 & 0.15 \\
\hline
\end{tabular}


The table VI analyzed the returns performance of SBI nifty index fund during the period of 2012-2017. In this table the highest excess return is 15.73 in the period of 2014 and the lowest excess return is -8.44 in the period of 2016 , the highest active return is 1.18 in the period of 2013 and the lowest return is -2.20 in the period of 2014 .

Table ViI Tata Index Fund Nifty Plan (G) - Annualized Returns (2012 - 2017)

\begin{tabular}{|c|c|c|c|c|c|c|c|}
\hline Year & Nifty sensex & Rm in \% & NAV & Rp in \% & Rf & Excess return(Rp-Rf) & Active return (Rp-Rm) \\
\hline 2012 & 5410.56 & 1.70 & 32.00 & 0.73 & 8.03 & -7.30 & -0.97 \\
\hline 2013 & 5908.09 & 9.20 & 35.35 & 10.47 & 8.85 & 1.62 & 1.27 \\
\hline 2014 & 7453.50 & 26.16 & 43.88 & 24.13 & 8.22 & 15.91 & -2.03 \\
\hline 2015 & 8298.82 & 11.34 & 49.20 & 12.10 & 7.25 & 4.85 & 0.76 \\
\hline 2016 & 8138.21 & -1.94 & 48.16 & -2.11 & 6.34 & -8.45 & -0.17 \\
\hline 2017 & $9,661.42$ & 18.72 & 57.11 & 18.59 & 6.42 & 12.17 & -0.12 \\
\hline
\end{tabular}

The table VII analyzed the returns performance of TATA index fund nifty plan(G) during the period of 2012-2017. In this table the highest excess return is 15.91 in the period of
2014 and the lowest excess return is -8.45 in the period of 2016, the highest active return is 1.27 in the period of 2013 and the lowest return is -2.03 in the period of 2014 .

TABLE VIII RISK ADJUSTED RETURNS

\begin{tabular}{|l|c|c|c|c|}
\hline \multicolumn{1}{|c|}{ Funds } & Alpha value & Beta value & Sharpe ratio & Treynor ratio \\
\hline IDBI Nifty Index Fund & -0.51 & 1.00 & 0.28 & 2.83 \\
\hline UTI Nifty Index Fund & 0.36 & 0.98 & 0.36 & 3.71 \\
\hline HDFC Index Fund - Nifty Plan & 0.45 & 0.97 & 0.35 & 3.81 \\
\hline SBI Nifty Index Fund & -0.37 & 1.03 & 0.31 & 2.99 \\
\hline Tata Index Fund-Nifty Plan(G) & -0.31 & 1.03 & 0.32 & 3.04 \\
\hline
\end{tabular}

The study further analyzed the risk-adjusted returns of the index mutual funds using Jensen's alpha (Table 8), Sharpe ratio and Treynor ratio. The study reveals that the in the case IDBI alpha was negative which shows the mutual fund scheme is not able to beat the market. In the case of SBI nifty index fund and TATA nifty index fund, which was statistically irrelevant. Among those index funds that tracked the CNX Nifty index, the HDFC Index Fund was performed best $r$ with an alpha of $0.45 \%$, followed by the UTI Index nifty Fund with an alpha of 0.36 . The analysis also showed that the beta value for all the funds, which indicates that the funds were closely correlated with their underlying index. The Sharpe ratio is positive in all the cases which are considered that the fund is acceptable. Treynor ratio also indicated the high positiveness that shows an investor has generated high returns.

TABLE IX TRACKING ERROR AND INFORMATION RATIO

\begin{tabular}{|l|c|c|}
\hline \multicolumn{1}{|c|}{ Fund } & $\begin{array}{c}\text { Tracking } \\
\text { Error }\end{array}$ & $\begin{array}{c}\text { Information } \\
\text { Ratio }\end{array}$ \\
\hline IDBI Nifty Index Fund & 1.28 & -0.4 \\
\hline UTI Nifty Index Fund & 1.32 & 0.24 \\
\hline HDFC Index Fund - Nifty Plan & 1.41 & 0.26 \\
\hline SBI Nifty Index Fund & 1.22 & -0.23 \\
\hline Tata Index Fund-Nifty Plan(G) & 1.19 & -0.18 \\
\hline
\end{tabular}

The tracking error also examined for the Index fund in relation to the underlying index Frino and Gallagher (2001) proposed various techniques for measuring the tracking errors. The most usually used approach of tracking error is the standard deviation of the difference between the returns of the benchmark index and index fund. The same method was adopted in the present study. Information ratio indicates the consistency of the fund manager in generating superior risk adjusted performance. A higher information ratio shows that fund manager has delivered consistent returns over a specified period.

Table IX indicates the tracking error of the index funds with respect to their underlying index. The study found the tracking error was positive and more than 1 in all the index fund which were examined in this study. The study revealed that tracking error were not much high of all the index funds. The table also shows the information ratios which were negative for IDBI nifty index fund, SBI nifty index fund and TATA nifty index fund. HDFC nifty index fund and UTI nifty index fund had a positive information ratio. So the information ratio shows that HDFC nifty index fund and UTI nifty index fund had a better portfolio.

\section{CONCLUSION}

An Index fund is mainly a passive Mutual Fund that allows investors to purchase a pool of securities in a single transaction. When an investor purchases a quantity of an index fund or ETF, it means that the investor is purchasing a share of a portfolio that contains the securities of the underlying index. Here the study has taken five nifty index 
fund (IDBI nifty index fund, UTI nifty index fund, HDFC nifty index fund, SBI nifty index fund, TATA nifty index fund) to evaluate the performance. The paper analyzed the performance of index mutual fund that tracked their underlying index, the CNX Nifty index. The study also evaluated Jensen's alpha for the index fund to know whether the fund managers are able to generate excess returns and the have a look at also found out Sharpe and treynor. The study revealed the tracking errors and information ratio of index funds.

\section{REFERENCES}

[1] Cheng-Ru Wu. (2008). A framework of assessable mutual fund performance, Journal of Modelling in Management, 3(2), 125-139

[2] Frino, A., \& Gallagher, D. R. (2001). Tracking S\&P 500 Index Funds. Journal of Portfolio Management, 28(1), 44-55.

[3] Inderjit Kaur \& Kaushik, K. P. (2015). Determinants of investment behaviour of investors towards mutual funds, Journal of Indian Business Research, 8(1), 19-42.
[4] Jayanthi, M., Malathy, S., Radhulya, T. (2013). A Study On Performance Of Gold ETF Companies In India, International Research Journal of Business and Management, 6, ISSN 2322-083X.

[5] Krishna Prasanna, P. (2012). Performance of Exchange-Traded Funds in India, International Journal of Business and Management, 7(23), ISSN 1833-3850 E-ISSN 1833-8119

[6] Muralidhar Prasad Ayaluru. (2016). Performance Analysis of Mutual Funds, Parikalpana - KIIT Journal of Management, 12(1).

[7] Narend, S. (2014, March). Performance of ETFs and Index Funds: A Comparative Analysis. NSE(National Stock Exchange),1-17. Retrieved From http://www.nseindia.com/research/content

[8] Shivangi Agarwal, Nawazish Mirza(2017), a study on the riskadjusted performance of mutual funds industry in india, Review of Innovation and Competitiveness, 3(1).

[9] Smita Shukla \& Rakesh Malusare. (2016). A Study on Performance of Indian Mutual Fund Schemes Investing in Overseas Securities. IOSR Journal of Business and Management (IOSR-JBM), e-ISSN: 2278-487X, p-ISSN: 2319-7668, 86-93,

[10] Vikas Choudhary, \& Preeti Sehgal Chawla. (2014). Performance Evaluation of Mutual Funds: A Study of Selected Diversified Equity Mutual Funds in India, International Conference on Business, Law and Corporate Social Responsibility (ICBLCSR'14). 